\title{
Ulna metaphyseal dysplasia syndrome
}

INSERM

\section{Source}

INSERM. (1999). Orphanet: an online rare disease and orphan drug data base. Ulna metaphyseal dysplasia syndrome. ORPHA:1837

Ulna metaphyseal dysplasia syndrome is a rare primary bone dysplasia characterized by dysplasia of the distal ulnar metaphyses, as well as metacarpal/metatarsal dysplasia and metaphyseal changes resembling enchondromata. Patients usually present bony swelling of the wrists with or without pain (knees and ankles may also be affected). Other variably associated features include platyspondyly, skeletal development delay, short stature and coxa valga. 